\title{
Structure-function relationship of antimicrobial peptide cathelicidin Pc-CATH1
}

\author{
Li DonG, ${ }^{\text {acc, }, \dagger}$ Juan-Juan YANG, ${ }^{b, \dagger}$ Ying WANG, ${ }^{\text {a,c }}$ Huan LiU, ${ }^{a}$ Li-Xian Mu, ${ }^{\text {a,c }}$ Dong-Hai Lin, ${ }^{\text {b,* }}$ \\ and Ren $\mathrm{LAI}^{\mathrm{a}, *}$
}

${ }^{a}$ Key Laboratory of Animal Models and Human Disease Mechanisms, Kunming Institute of Zoology, Chinese Academy of Sciences, Kunming 650223, Yunnan, China

${ }^{b}$ Department of Chemistry, College of Chemistry and Chemical Engineering, and the Key Laboratory for Chemical Biology of Fujian Province, Xiamen University, Xiamen 361005, Fujian, China

${ }^{\mathrm{c}}$ Graduate University of Chinese Academy of Sciences, Beijing 100049, China

${ }^{\dagger}$ These authors contributed equally to this work.

\begin{abstract}
Cathelicidin Pc-CATH1 is a cathelicidin-derived myeloid antimicrobial peptide identified from Phasianus colchicus with strong antimicrobial activity against most of bacteria and fungi tested, including the clinically isolated (IS) drug-resistant strains. Considering the uniform distribution of net positive charge in both $\mathrm{C}$ - and $\mathrm{N}$-terminus sequence of cathelicidin Pc-CATH1 and most of hydrophobic amino acid (aa) residues positioned in middle of the sequence, the antimicrobial peptide was used to investigate the structure-function relationship by truncating gradually $\mathrm{N}$ - or $\mathrm{C}$-terminus amino acid residue. More than 10 modified peptide homologues (20-26 aa length) of cathelicidin Pc-CATH1 were found to keep strong antimicrobial abilities. The possible relationships between bioactivities including antimicrobial and hemolytic abilities, components of secondary structure, hydrophobicity, amphipathicity, net charge, and sequence length were investigated. The current work provided suggestions for structural and functional modification of linear, $\alpha$-helical antimicrobial peptides containing no disulfided bridges.
\end{abstract}

Keywords: cathelicidin, antimicrobial peptide, structure-function relationship

\section{Introduction}

Antimicrobial peptides are important components of the innate immunity system, which is the first line of host defense protecting living organisms from microorganism attacking. These molecules are gene-encoded, cationic, and have a broad activity against bacteria, fungi, virus, and even some tumor cells. The diversity of antimicrobial peptides is very rich. Based on the amino acid sequence and secondary structure, they are classified into several groups. In mammals, cathelicindin and defensin are the two main antimicrobial peptide groups ${ }^{1,2}$.

Cathelicidin is synthesized as pre-pro-protein containing a $\mathrm{N}$-terminal signal domain, a highly conserved cathelin domain, and the varible $\mathrm{C}$-terminal peptide ${ }^{3}$. Cathelicidin is named for the cathelin domain as it is very similar to cathelin protein, a cathepsin L inhibitor originally isolated from pig leucocytes ${ }^{4}$. The variable $\mathrm{C}$-terminal peptide is mature peptide. It is considerably diverse in amino acid sequence. Based on the structure of mature peptide, cathelicidin can be classified into three groups, linear, $\alpha$-helical peptides without cysteine, $\beta$ -

*To whom correspondence should be addressed. E-mail: dhlin@xmu.edu.cn (D.H. Lin); rlai@mail.kiz.ac.cn (R. Lai). hairpin peptides with cysteines by disulphides, peptides rich in one or two amino acids. As the active region, the mature peptides display typical features of antimicrobial peptide, cationic and amphipathic, cathelicidin Pc-CATH1 is a potential antimicrobial peptide found in $P$. colchicus. Most MIC values against Gram-positive bacteria were in the range of $0.09-2.95 \mu \mathrm{M}$ in the presence of $100 \mathrm{mM} \mathrm{NaCl}$. Two obvious characteristics are found in the sequence of cathelicidin Pc-CATH1. One is the uniform distribution of three positive charged amino acid residues (Arg or Lys) in both C- and Nterminus sequence. Another one is that most of the hydrophobic amino acid residues are positioned in the middle of the sequence. The unique structural characteristic of cathelicidin Pc-CATH1 provide excellent template to study the structurefunction relationship.

\section{Results and Discussion}

Cathelicidin Pc-CATH1 and its 29 homologues were listed in Table 1 . They are 11-26 aa in length. There are 4-8 net positive charges. Their hydrophobicity is from 0.122 to 0.640 . The hydrophobic moment ranges from 0.285 to 0.645 . The percent ratio of nonpolar residues is from $50 \%$ to $66.67 \%$.

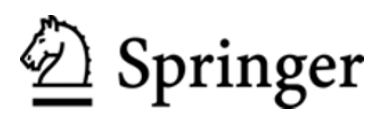


Table 1. Sequences and structural parameters of peptides

\begin{tabular}{|c|c|c|c|c|c|c|}
\hline name & sequence & net & hydrophobicity & hydrophobic moment & polar residues $(\mathrm{n} \%)$ & nonpolar residues (n\%) \\
\hline LR1 & RIKRFWPVVIRTVVAGYNLYRAIKKK & $6+8$ & 0.421 & 0.406 & $11 / 42.31$ & $15 / 57.69$ \\
\hline LR2 & RIKRFWPVVIRTVVAGYNLYRAIKK & ‘+7 & 0.477 & 0.412 & $10 / 40$ & $15 / 60$ \\
\hline LR3 & RIKRFWPVVIRTVVAGYNLYRAIK & ‘+6 & 0.538 & 0.391 & $9 / 37.5$ & $15 / 62.5$ \\
\hline LR4 & RIKRFWPVVIRTVVAGYNLYRAI & $‘+5$ & 0.605 & 0.435 & $8 / 34.78$ & $15 / 65.22$ \\
\hline LR5 & RIKRFWPVVIRTVVAGYNLYRA & $‘+5$ & 0.550 & 0.407 & $8 / 36.36$ & $14 / 63.64$ \\
\hline LR6 & RIKRFWPVVIRTVVAGYNLYR & $‘+5$ & 0.562 & 0.441 & $8 / 38.1$ & $13 / 61.9$ \\
\hline LR7 & RIKRFWPVVIRTVVAGYNLY & $‘+4$ & 0.640 & 0.456 & $7 / 35$ & $13 / 65$ \\
\hline LR8 & RIKRFWPVVIRTVVAGYNL & $‘+4$ & 0.624 & 0.430 & $7 / 36.84$ & $12 / 63.16$ \\
\hline LR9 & RIKRFWPVVIRTVVAGYN & $‘+4$ & 0.564 & 0.490 & $7 / 38.89$ & $11 / 61.11$ \\
\hline LR10 & RIKRFWPVVIRTVVAGY & $‘+4$ & 0.632 & 0.492 & $6 / 35.29$ & $11 / 64.71$ \\
\hline LR11 & RIKRFWPVVIRTVVAG & $‘+4$ & 0.612 & 0.478 & $6 / 37.5$ & $10 / 62.5$ \\
\hline LR12 & RIKRFWPVVIRTVVA & ${ }^{\prime}+4$ & 0.653 & 0.510 & $5 / 33.33$ & $10 / 66.67$ \\
\hline LR13 & RIKRFWPVVIRTVV & $‘+4$ & 0.677 & 0.566 & $5 / 35.71$ & $9 / 64.29$ \\
\hline LR14 & RIKRFWPVVIRTV & ‘ +4 & 0.635 & 0.638 & $5 / 38.46$ & $8 / 61.54$ \\
\hline LR15 & RIKRFWPVVIRT & ${ }^{\prime}+4$ & 0.587 & 0.592 & $5 / 41.67$ & $7 / 58.33$ \\
\hline LR16 & RIKRFWPVVIR & ‘+4 & 0.616 & 0.645 & $4 / 36.36$ & $7 / 63.64$ \\
\hline RL1 & IKRFWPVVIRTVVAGYNLYRAIKKK & $‘+7$ & 0.478 & 0.425 & $10 / 40$ & $15 / 60$ \\
\hline RL2 & KRFWPVVIRTVVAGYNLYRAIKKK & $‘+7$ & 0.423 & 0.372 & $10 / 41.67$ & $14 / 58.33$ \\
\hline RL3 & RFWPVVIRTVVAGYNLYRAIKKK & ‘ +6 & 0.484 & 0.368 & $9 / 39.13$ & $14 / 60.87$ \\
\hline RL4 & FWPVVIRTVVAGYNLYRAIKKK & ${ }^{\prime}+5$ & 0.552 & 0.348 & $8 / 36.36$ & $14 / 63.64$ \\
\hline RL5 & WPVVIRTVVAGYNLYRAIKKK & $\cdot+5$ & 0.493 & 0.306 & $8 / 38.1$ & $13 / 61.9$ \\
\hline RL6 & PVVIRTVVAGYNLYRAIKKK & ${ }^{\prime}+5$ & 0.406 & 0.260 & $8 / 40$ & $12 / 60$ \\
\hline RL7 & VVIRTVVAGYNLYRAIKKK & $`+5$ & 0.389 & 0.311 & $8 / 42.11$ & $11 / 57.89$ \\
\hline RL8 & VIRTVVAGYNLYRAIKKK & ${ }^{\prime}+5$ & 0.343 & 0.337 & $8 / 44.44$ & $10 / 55.56$ \\
\hline RL9 & IRTVVAGYNLYRAIKKK & ${ }^{\prime}+5$ & 0.291 & 0.285 & $8 / 47.06$ & $9 / 52.94$ \\
\hline RL10 & RTVVAGYNLYRAIKKK & ${ }^{\prime}+5$ & 0.197 & 0.334 & $8 / 50$ & $8 / 50$ \\
\hline RL11 & TVVAGYNLYRAIKKK & $‘+4$ & 0.277 & 0.304 & $7 / 46.67$ & $8 / 53.33$ \\
\hline RL12 & VVAGYNLYRAIKKK & ‘ +4 & 0.279 & 0.311 & $6 / 42.86$ & $8 / 57.14$ \\
\hline RL13 & VAGYNLYRAIKKK & $'+4$ & 0.206 & 0.300 & $6 / 46.15$ & $7 / 53.85$ \\
\hline RL14 & AGYNLYRAIKKK & ‘+4 & 0.122 & 0.427 & $6 / 50$ & $6 / 50$ \\
\hline
\end{tabular}

There are no acidic residues in these peptides. As illustrated in Fig. 1. All of LR homologues (LR1-LR16) and most of RL homologues show the amphipathicity, with the hydrophobic residues in the lower regions and the hydrophilic residues in the upper regions. Some of RL homologues, such as RL11-14, are hydrophilic, and are not amphipathic.

To investigate the secondary structures of cathelicidin PcCATH1 and its homologues in membrane-like environments, the CD spectra of these peptides were analyzed at a variety of membrane-mimicking conditions (Fig. 2). As shown in Fig. $2 \mathrm{~A}$, these peptides showed unordered structures in aqueous solution; main secondary components are random and $\beta$-sheet. These peptides exhibited conformational changes in SDS micelles. There are high percent $(>25 \%) \alpha$-helical structure component in most of these peptides resolved in all membrane-mimetic environments. Their CD spectrum exhibited characteristic double negative maxima at 205 and $220 \mathrm{~nm}$, suggesting that it can adopt a significant degree of $\alpha$-helical structure under these conditions. These results suggest that most of these peptides have a more folded structure in negatively charged environments due to electrostatic interaction. Some peptides (LR11-16, RL14) adopt a lower degree of $\alpha$-helical structure in SDS micelles.

The antimicrobial activities of cathelicidin Pc-CATH1 and its 29 homologues against a representative set of bacterial and fungi strains, including $S$. aureus, B. subtilis, E. coli, and $C$. albicans were assayed as listed in Table 2, and compared with the activities of amphicillin. Nine peptides including LR1-4 and RL1-5 showed strong antimicrobial activities. Most of the MICs against all the four microorganisms were less than $10 \mu \mathrm{g} / \mathrm{mL}$. Especially, the MICs against C. albicans were 0.586 to $7.032 \mu \mathrm{g} / \mathrm{mL}$. It seems that these peptides showed the strongest antimicrobial abilities against the fungus, $C$. albicans. For $S$. aureus, RL1-5 (MICs $1.172-14.063 \mu \mathrm{g} / \mathrm{mL}$ ) showed stronger antimicrobial activities than LR1-4 did (MICs 7.032$37.5 \mu \mathrm{g} / \mathrm{mL}$ ). LR5 showed antimicrobial abilities against three tested microorganism strains including $S$. aureus, E. coli, and C. albicans but B. subtilis. LR6-8 showed antimicrobial abilities against two tested microorganism strains including $E$. coli, and C. albicans. RL6 contained antimicrobial activities against both $S$. aureus and C. albicans. LR9-11, LR13, LR15 and 16, RL7 and 8 showed antimicrobial activities against only C. albicans. For LR peptides, only LR12 and LR14 had no antimicrobial activity.

As illustrated in Fig. 3, several cathelicidin Pc-CATH1 homologues showed strong hemolytic activities against human blood red cells. LR1-3 and RL1-4 showed much stronger hemolytic activities than other cathelicidin Pc-CATH1 homologues. At the concentration of $200 \mu \mathrm{g} / \mathrm{mL}, \mathrm{LR} 1-3$ induced approximate $30 \%, 26 \%$, and $25 \%$ hemolysis of human blood red cells, respectively; RL1-4 induced approximate $24 \%, 48 \%$, $58 \%$, and $57 \%$ hemolysis, respectively (Fig. 3A). Their hemolytic activities were in a dose-dependent manner as illustrated

\section{Springer}



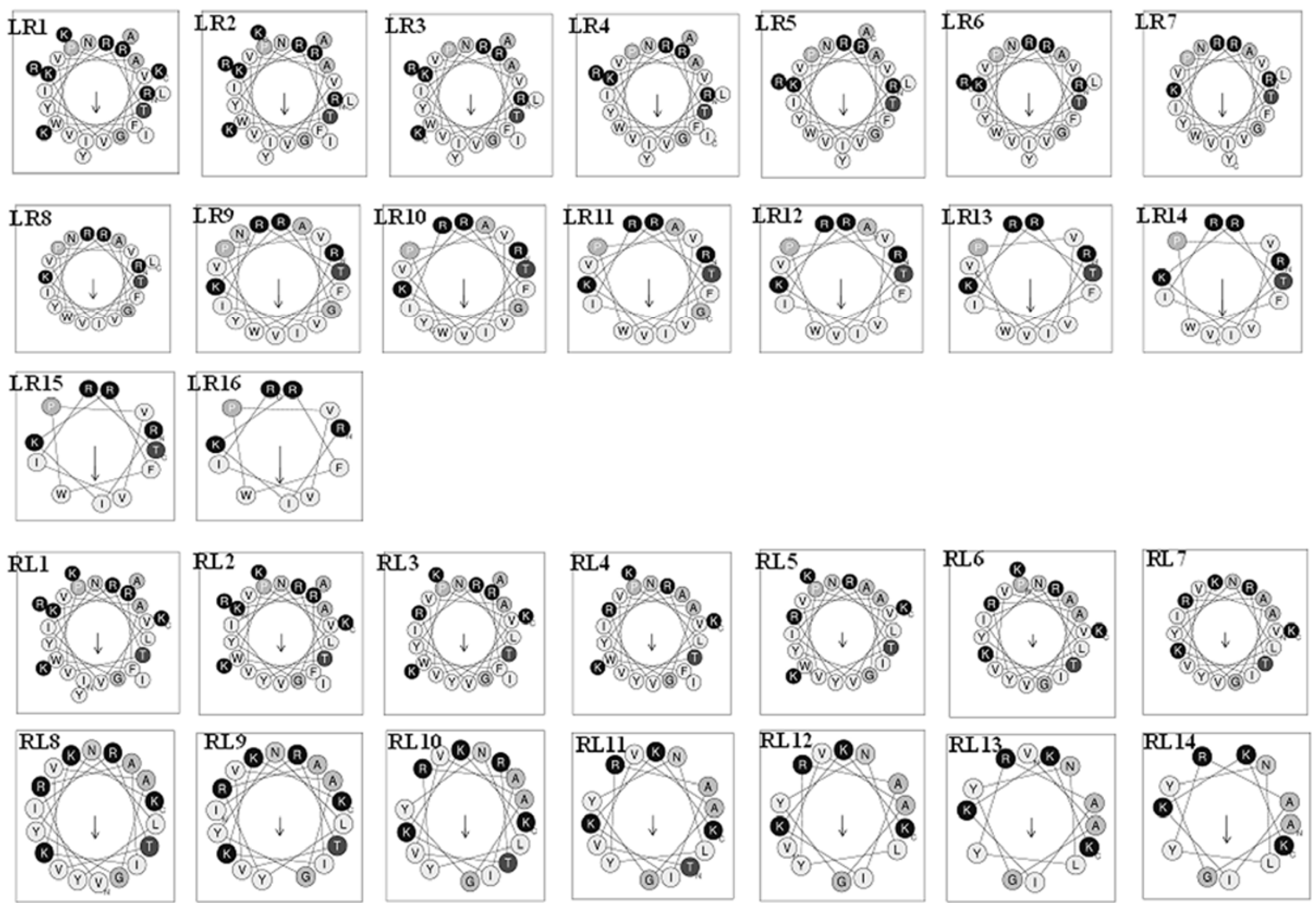

Figure 1. Helix-wheel plots of cathelicidin Pc-CATH1 and its homologues. The hydrophobic residues are indicated in gray, and the hydrophilic residues are shown in black.

in Fig. 3B. LR8-11, RL6, and RL14 did not show hemolytic ability in this experiment.

LR2 (MIC against four tested microorganism strains was $3.516,4.688,9.375$, and $2.344 \mu \mathrm{g} / \mathrm{mL}$, respectively) and LR3 (MIC against four tested microorganism strains was 2.344, $4.688,7.032$, and $0.586 \mu \mathrm{g} / \mathrm{ml}$, respectively) showed stronger antimicrobial abilities than the native cathelicidin Pc-CATH1 (LR1, MIC against four tested microorganism strains was $9.375,18.75,9.375$, and $7.032 \mu \mathrm{g} / \mathrm{mL}$ ). Especially, LR3 showed much stronger antimicrobial activities than LR1 although LR3 just has six positively charged residues. Table 1 showed that hydrophobicity degree among these three peptides is $\operatorname{LR} 3(0.538)>\operatorname{LR} 2(0.477)>\operatorname{LR} 1(0.421)$. Coincidently, antimicrobial activity among these three peptides is LR3 > LR2 > LR1. It seems that the hydrophobicity is positively correlated with antimicrobial ability in these three peptides. LR4-6 lost their three lysines positioned at the C-terminus and had only 5 net positive charges, which obviously increased the hydrophobicity $(0.605,0.550$, and 0.562 , respectively) and resulted in losing amphipathicity at the C-terminus. Decreased net positive charge and the lacking of amphipathicity at the C-terminus may contribute to their decreased antimicrobial and hemolytic activities. Other LR peptides had a little $\alpha$-helix ratio (Fig. 2), which possibly result in weak antimicrobial and hemolytic activities.
Several RL (RL1-5) peptides showed stronger antimicrobial and hemolytic activities than LR1-5 although they had similar length and net positive charges. RL1-5 had weaker hydrophobicity and hydrophobicity moment than LR1-5, which are possible contributable for the strong antimicrobial and hemolytic abilities of RL1-5. RL6 is less one residue (Trp) at the N-terminus than RL5. There are higher percent $\alpha$-helical structure component in RL6 (62\%) than in RL5 (42\%) while the antimicrobial activities of RL6 was much weaker than those of RL5 (Fig. 2, Table 2). It has been found that hydrophobicity of RL6 (0.406) is lower than that of RL5 (0.493). The hydrophobicity of RL6 is so low that it is difficult to keep its amphipathicity as illustrated in Fig. 1. The tryptophan residues in some antimicrobial peptides including melittin, IsCT, papiliocin, and mastoparan B have been reported to be critical for their antibacterial and/or hemolytic activities $^{7-10}$. In those antimicrobial peptides, the tryptophan residues are located in the hydrophobic core of the peptides, exhibit restricted motion in bacterial membrane, and are involved in hydrophobic interactions with the acyl chains of the membrane phospholipid ${ }^{7-10}$. As illustrated in Fig. 1, the tryptophan residues in RL peptides are located in the hydrophobic core of the peptides while RL6 lacks tryptophan. The absence of tryptophan and low degree of amphipathicity 

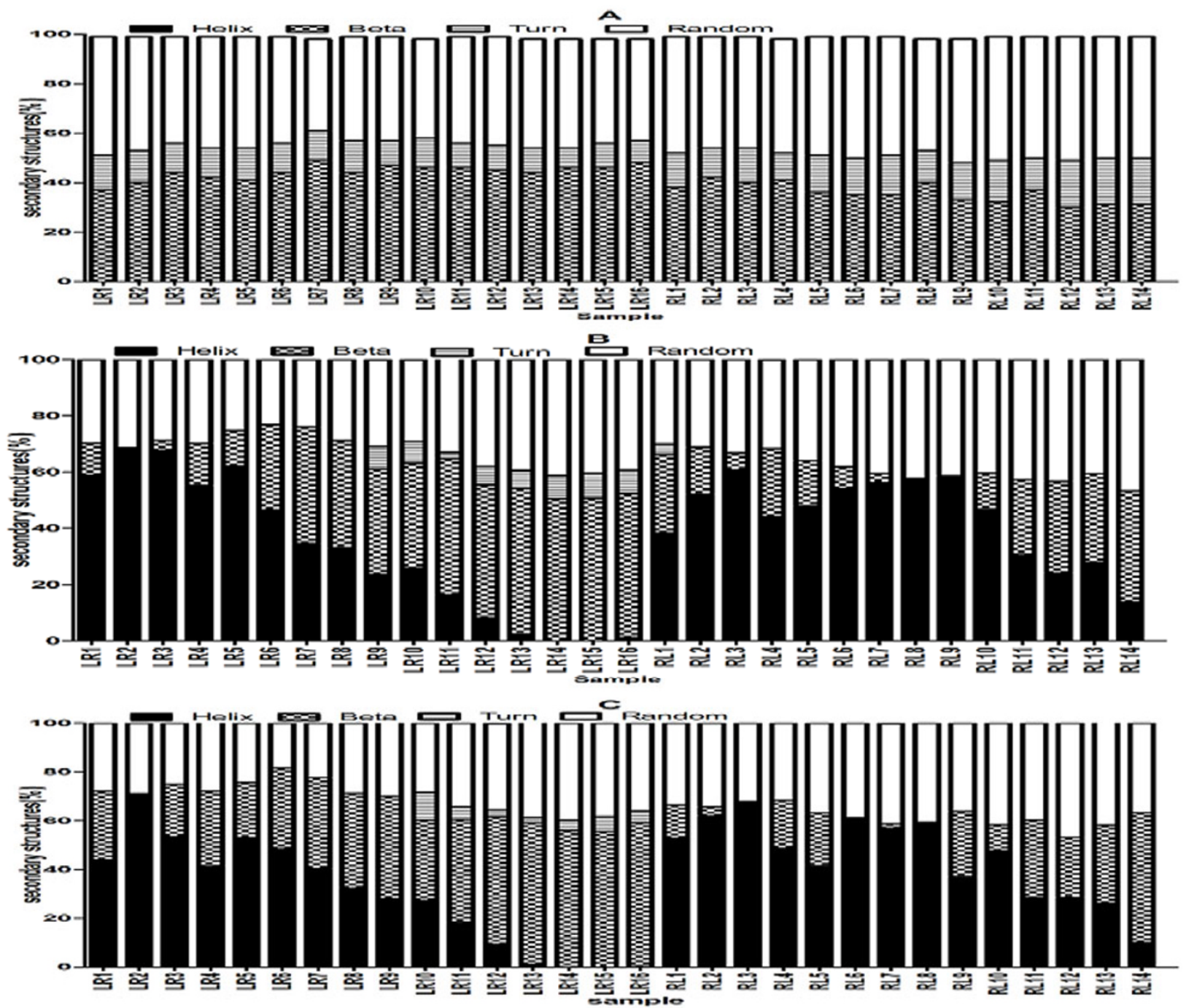

Figure 2. $\mathrm{CD}$ spectra of peptides $(90 \mu \mathrm{M}, \mathrm{pH} 5.5)$ in $\mathrm{H}_{2} \mathrm{O}(\mathrm{A}), 30$ (B), and $60 \mathrm{mM}$ (C) SDS micelles micelles. These values represent mean values of three independent experiments.

in RL6 may result in its low antimicrobial activities.

The hemolytic activity between RL4 and RL5 had big difference although there is only one amino acid residue (Phe) difference between them (Table 1). At the concentration of $200 \mu \mathrm{g} / \mathrm{mL}$, RL4 induced $57 \%$ hemolysis while RL5 only induced $8 \%$ hemolysis. For RL4, there is one additional Phe extension at the N-terminus of RL5. Beside its involvement in antimicrobial ability, tryptophan residues in antimicrobial peptides were also reported to be involved in hemolytic activities $^{7-9}$. The tryptophan is located the position 2 and the position 1 at the N-terminus of RL4 and RL5, respectively (Table 1). The tryptophan residue located at the position 1 should be more flexible than the tryptophan residue located at the position 2 . Therefore, the anchoring ability of Trp 1 into the membrane of blood red cells might be weaker than that of Trp2. In addition, phenylalanine residue has also ability to anchor into the membrane of blood red cells, the deletion of phenylalanine in RL5 can also decrease its hemolytic activity.

The current work investigated the structure-function relationship of antimicrobial peptide cathelicidin Pc-CATH1 to screen peptide candidates with potential antimicrobial abilities and low hemolytic activities. Some cathelicidin Pc-CATH1 homologues such as LR4 and RL5 have been found to be potent templates for developing antibiotics. Their structure-function relationships responsible for antimicrobial and hemolytic activities will be investigated further.

\section{Experimental Section}

General Experimental Procedures. The analysis for helixwheel diagrams, net charge, hydrophobicity, hydrophobicity moment, polar residues, and nonpolar residues were carried out by the software package provided by The Expert Protein Analysis System (ExPASy) proteomics server according to the method described by Gautier et $\mathrm{al}^{11}$. (http://heliquest.ipmc.cnrs. $\mathrm{fr} /$ ). The experiments and data analysis of circular dichroism (CD) were performed at $298 \mathrm{~K}$ using a JASCO J-810 spectropolarimeter (Jasco, Japan).

\section{算 Springer}



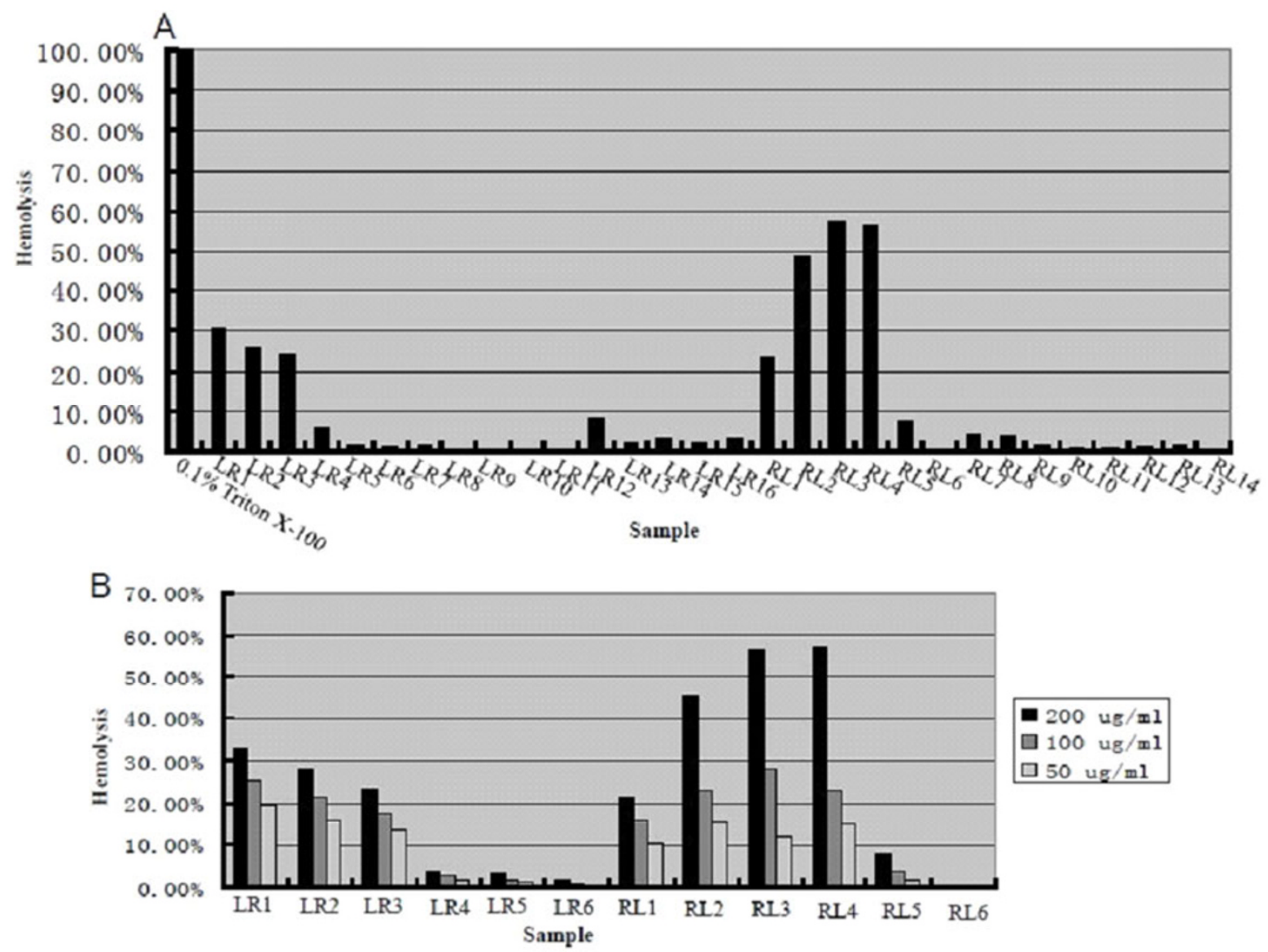

Figure 3. Hemolytic activities of cathelicidin Pc-CATH1 and its homologues against human blood red cells. A: Hemolytic activities of peptides at concentration of $200 \mu \mathrm{g} / \mathrm{mL}$; B: hemolytic activities of LR1-6 and RL1-6 at concentration of 50, 100, and $200 \mu \mathrm{g} / \mathrm{mL}$, respectively. These values represent mean values of three independent experiments.

Experimental Material. Cathelicidin Pc-CATH1 and its 29 homologues (Table 1) were synthesized by GL Biochem (Shanghai) Ltd. (Shanghai, China). Their purity was confirmed higher than $98 \%$ by HPLC and mass spectrometry analysis.

Hemolytic Activities. The hemolytic activities of cathelicidin Pc-CATH1 and its 29 homologues against human red blood cells were tested in Alsever's solution (in $\mathrm{g} / \mathrm{L}: \mathrm{NaCl}, 4.2$; citric Acid $\cdot 3 \mathrm{Na} \cdot 2 \mathrm{H}_{2} \mathrm{O}, 8.0$; citric Acid $\cdot \mathrm{H}_{2} \mathrm{O}, 0.55$; D-glucose, 20.5 ) as reported $^{12}$. Fresh human red blood cells were washed three times with Alsever's solution by centrifugation for $10 \mathrm{~min}$ at $1000 \times \mathrm{g}$. The washed human red blood cells were resuspended in Alsever's solution. The tested samples (resolved in $50 \mu \mathrm{L}$ Alsever's solution) were mixed with $50 \mu \mathrm{L}$ human red blood cells in Alsever's solution. The final erythrocyte concentration is $4 \%(\mathrm{v} / \mathrm{v})$. The resulting solution was incubated at $37{ }^{\circ} \mathrm{C}$ for $30 \mathrm{~min}$. Red cells were centrifuged at $1000 \times \mathrm{g}$ for $5 \mathrm{~min}$ and the absorbance of the supernatant was measured at $595 \mathrm{~nm}$. $100 \%$ hemolysis was determined by adding $0.1 \%$ Triton $\mathrm{X}-100$ to a sample of cells.

Circular Dichroism Analysis. Samples were prepared by dissolving tested peptide powders $(90 \mu \mathrm{M})$ in membrane- mimetic environments (SDS micelles of different concentrations). The CD spectra of the peptides were recorded at $25^{\circ} \mathrm{C}$. The spectra were measured between 190 and $250 \mathrm{~nm}$ using $0.1 \mathrm{~cm}$ path-length cell with $0.1 \mathrm{~nm}$ bandwidth. The response time is $1 \mathrm{sec}$; the scan speed is $100 \mathrm{~nm} / \mathrm{min}$. Ten consecutive scans were performed for each sample. The data from ten scans were averaged and smoothed using J810 software. The secondary structure elements of the peptides were estimated according to the Yang formula ${ }^{13}$.

Antimicrobial Testing. Gram-positive bacterium Staphylococcus aureus (ATCC25923), Bacillus subtilis Gram-negative bacteria Escherichia coli ATCC25922, and fungus Candida albicans (ATCC2002) were obtained from Kunming Medical College (Yunnan, China). Antimicrobial assay was carried out according to our previous method ${ }^{14,15}$. Microorganisms were first cultured in LB (Luria-Bertani) broth. When the absorbance of the culture at $600 \mathrm{~nm}$ was up to 0.8 , a $10 \mu \mathrm{L}$ aliquot of the microorganism culture was then taken and mixed with $8 \mathrm{~mL}$ of fresh LB broth with $0.7 \%$ agar (upper agar). The upper agar was poured onto a $90 \mathrm{~mm}$ Petri dish containing $25 \mathrm{~mL}$ of $1.5 \%$ agar in LB broth (lower agar). A $20 \mu \mathrm{L}$ aliquot of the test sample filtered on a $0.22 \mu \mathrm{m}$ was dropped onto strips of

\section{是 Springer}


Table 2. Antimicrobial activities of cathelicidin Pc-CATH1 and its 29 homologues

\begin{tabular}{lcccc}
\hline & \multicolumn{4}{c}{ MIC $(\mu \mathrm{g} / \mathrm{ml})$} \\
\cline { 2 - 5 } sample & E. coli & B. subtilis & S. aureus & C. albicans \\
\hline ampicillin & 2.344 & 9.375 & 37.5 & 0.146 \\
LR1 & 9.375 & 18.75 & 9.375 & 7.032 \\
LR2 & 3.516 & 4.688 & 9.375 & 2.344 \\
LR3 & 2.344 & 4.688 & 7.032 & 0.586 \\
LR4 & 9.375 & 37.5 & 37.5 & 2.344 \\
LR5 & 4.688 & $\mathrm{~N}$ & 75 & 4.688 \\
LR6 & 9.375 & $\mathrm{~N}$ & $\mathrm{~N}$ & 9.375 \\
LR7 & 150 & $\mathrm{~N}$ & $\mathrm{~N}$ & 112.5 \\
LR8 & 200 & $\mathrm{~N}$ & $\mathrm{~N}$ & 75 \\
LR9 & $\mathrm{N}$ & $\mathrm{N}$ & $\mathrm{N}$ & 150 \\
LR10 & $\mathrm{N}$ & $\mathrm{N}$ & $\mathrm{N}$ & 75 \\
LR11 & $\mathrm{N}$ & $\mathrm{N}$ & $\mathrm{N}$ & 150 \\
LR12 & $\mathrm{N}$ & $\mathrm{N}$ & $\mathrm{N}$ & $\mathrm{N}$ \\
LR13 & $\mathrm{N}$ & $\mathrm{N}$ & $\mathrm{N}$ & 150 \\
LR14 & $\mathrm{N}$ & $\mathrm{N}$ & $\mathrm{N}$ & $\mathrm{N}$ \\
LR15 & $\mathrm{N}$ & $\mathrm{N}$ & $\mathrm{N}$ & 150 \\
LR16 & $\mathrm{N}$ & $\mathrm{N}$ & $\mathrm{N}$ & 150 \\
RL1 & 9.375 & 2.344 & 3.516 & 0.586 \\
RL2 & 18.75 & 3.516 & 3.516 & 0.586 \\
RL3 & 19.75 & 7.032 & 1.172 & 0.586 \\
RL4 & 28.125 & 3.516 & 1.172 & 0.879 \\
RL5 & 37.5 & 37.5 & 14.063 & 2.344 \\
RL6 & $\mathrm{N}$ & $\mathrm{N}$ & 100 & 37.5 \\
RL7 & $\mathrm{N}$ & $\mathrm{N}$ & $\mathrm{N}$ & 56.25 \\
RL8 & $\mathrm{N}$ & $\mathrm{N}$ & $\mathrm{N}$ & 75 \\
RL9 & $\mathrm{N}$ & $\mathrm{N}$ & $\mathrm{N}$ & $\mathrm{N}$ \\
RL10 & $\mathrm{N}$ & $\mathrm{N}$ & $\mathrm{N}$ & $\mathrm{N}$ \\
RL11 & $\mathrm{N}$ & $\mathrm{N}$ & $\mathrm{N}$ & $\mathrm{N}$ \\
RL12 & $\mathrm{N}$ & $\mathrm{N}$ & $\mathrm{N}$ & $\mathrm{N}$ \\
RL13 & $\mathrm{N}$ & $\mathrm{N}$ & $\mathrm{N}$ & $\mathrm{N}$ \\
RL14 & $\mathrm{N}$ & $\mathrm{N}$ & $\mathrm{N}$ & $\mathrm{N}$ \\
\hline MIC: & $\mathrm{N}$ & $\mathrm{N}$ & $\mathrm{N}$ & \\
\hline
\end{tabular}

MIC: minimal inhibitory concentration. These concentrations represent mean values of three independent experiments performed in duplicates. N: no antimicrobial activity was found at the sample concentration up to $200 \mu \mathrm{g} / \mathrm{mL}$.

Whatman no. 3 filter paper with a diameter of $0.3 \mathrm{~cm}$. The strips were allowed to dry at room temperature for approximately $2 \mathrm{~h}$ and put on the surface of the hardened upper agar. If an examined sample contained antimicrobial activity, a clear zone formed on the surface of the top agar representing inhibition of microorganism growth. MICs (minimal inhibitory concentration) of tested samples against these microorganisms were determined using a broth microdilution assay as our previous reports ${ }^{15,16}$. The MIC was defined as the lowest concentration of test peptides inhibiting microorganism growth.

\section{Acknowledgments}

This work was supported by Chinese National Natural Science Foundation (31070701, 31000962, 31025025, 30730026), the Program of Shanghai Subject Chief Scientist (NO.09XD1405100), the Ministry of Science and Technology (2010CB529800, 2009ZX09103-1/091, 2011ZX09102-002$10)$ and the Ministry of Agriculture (2009ZX08009-159B).

Open Access This article is distributed under the terms of the Creative Commons Attribution License which permits any use, distribution, and reproduction in any medium, provided the original author(s) and source are credited.

\section{References}

[1] Shi, Q. W.; Su, X. H.; Kiyota, H. Chem. Rev. 2008, 108, 42954327.

[1] Zasloff, M. Nature 2002, 415, 389-395.

[2] Bulet, P.; Stocklin, R.; Menin, L. Immunol. Rev. 2004, 198, 169184.

[3] Yamasaki, K.; Gallo, R. L. Eur. J. Dermatol. 2008, 18, 11-21.

[4] Ritonja, A.; Kopitar, M.; Jerala, R.; Turk, V. FEBS. Lett. 1989, $255,211-214$.

[5] Tomasinsig, L.; Zanetti, M. Curr. Protein. Pept. Sci. 2005, 6, $23-$ 34.

[6] Wang, Y.; Lu, Z.; Feng, F.; Zhu, W.; Guang, H.; Liu, J.; He, W.; Chi, L.; Li, Z.; Yu, H. Dev. Comp. Immunol. 2011, 35, 314-322.

[7] Ghosh, A. K.; Rukmini, R.; Chattopadhyay, A. Biochemistry 1997, 36, 14291-14305.

[8] Yu, K.; Kang, S.; Park, N.; Shin, J.; Kim, Y. J. Pept. Res. 2000, $55,51-62$.

[9] Lim, S. S.; Kim, Y.; Park, Y.; Kim, J. L.; Park, I. S.; Hahm, K. S.; Shin, S.Y. Biochem. Biophys. Res. Commun. 2005, 334, 13291335.

[10] Kim, J. K.; Lee, E.; Shin, S.; Jeong, K. W.; Lee, J. Y.; Bae, S. Y.; Kim, S. H.; Lee, J.; Kim, S. R.; Lee, D. G.; Hwang, J. S.; Kim, Y. J. Biol. Chem. 2011, 286, 41296-41311.

[11] Gautier, R.; Douguet, D.; Antonny, B.; Drin, G. Bioinformatics 2008, 24, 2101-2102.

[12] Bignami, G. S. Toxicon 1993, 31, 817-820.

[13] Chang, C. T.; Wu, C. S.; Yang, J. T. Anal. Biochem. 1978, 91, $13-31$

[14] Lai, R.; Zheng, Y. T.; Shen, J. H.; Liu, G. J.; Liu, H.; Lee, W. H.; Tang, S. Z.; Zhang, Y. Peptides 2002, 23, 427-435.

[15] Li, J. X.; Zhang, C.; Xu, X. Q.; Wang, J.; Yu, H. N.; Lai, R.; Gong, W. M. Faseb J. 2007, 21, 2466-2473.

[16] Li, J. X.; Xu, X. Q.; Xu, C. H.; Zhou, W. P.; Zhang, K. Y.; Yu, H. N.; Zhang,Y. P.; Zheng, Y. T.; Rees, H. H.; Lai, R.; Yang, D. M.; Wu, J. Mol. Cell. Proteomics 2007, 6, 882-894. 